l'd like to teach the world to sing: Music and conflict transformation by Arild Bergh

\title{
l'd like to teach the world to sing: Music and conflict transformation
}

\author{
Arild Bergh
}

Submitted by Arild Bergh, to the University of Exeter as a thesis for the degree of Doctor of Philosophy by Research in Sociology, January 2010.

This thesis is available for Library use on the understanding that it is copyright material and that no quotation from the thesis may be published without proper acknowledgement.

I certify that all material in this thesis which is not my own work has been identified and that no material has previously been submitted and approved for the award of a degree by this or any other University.

(signature) 
I'd like to teach the world to sing: Music and conflict transformation by Arild Bergh

\section{Abstract}

Modern conflict transformation emerged after World War II as a discipline and a field of academic research. Since the early 1990s it has increasingly concerned itself with psycho-social issues (e.g. trauma treatment or reconciliation) in the aftermath of violent protracted social conflicts. Within this psycho-social space there has been a growing interest in the use of music in conflict transformation to improve relationships between in and out-groups. However, the field of music and conflict transformation is still nascent, with little in-depth research available. The majority of studies have been undertaken by interested parties or relies on anecdotal evidence from organisers and musicians with little concern for the context of the music use. Participants, whose attitudes and relationships to out-groups are the focus of conflict transformation interventions, are largely overlooked and their views are rarely discussed. Furthermore, there are few detailed studies on exactly how music affects conflict transformation outcomes. Instead allusions are often made to terms such as "the power of music" which act as a black box intended to explain how music "works", but patently fail to do so.

This thesis attempts to fill these two gaps in the literature by focusing on the participants' experiences in two different conflict transformation contexts, a multicultural music project for school children in Noway and the casual music use in a settlement of internally displaced persons in Sudan. Through qualitative research methods, rich descriptive data from different parties is gathered. The data is analysed using grounded theory. As a result a very different and more complex picture emerges that enriches the current understanding of how music is used and perceived in conflict transformation contexts. In particular, how participants view these activities and how power relationships, though rarely mentioned, affect the music use is explored in detail. Some tentative suggestions indicate that music works best when used in longitudinal bottom-up activities and that music can augment conflict transformation activities rather than replace them. Additionally, it is proposed that music may work as a form of benign interruption in conflict transformation activities and that musical events provide a liminal space where the real work lies in the process of bringing any changes in attitudes from the liminal space into everyday life. 
I'd like to teach the world to sing: Music and conflict transformation by Arild Bergh

\section{Table of Contents}

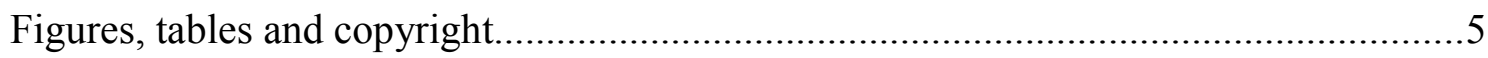

Preface: How singing stopped war - but not alone.............................................. 6

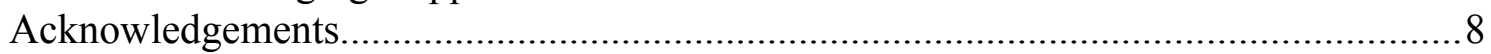

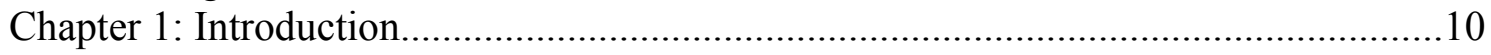

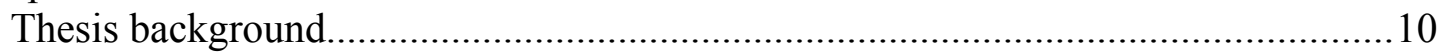

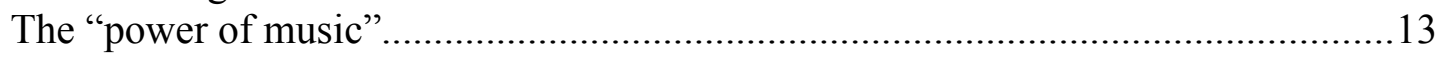

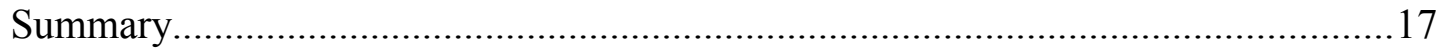

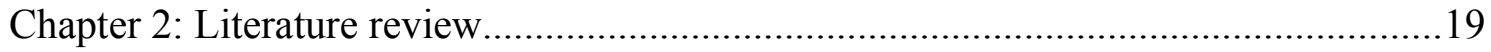

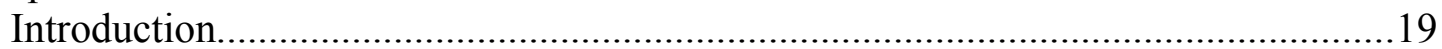

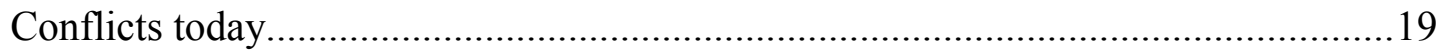

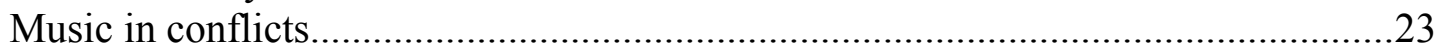

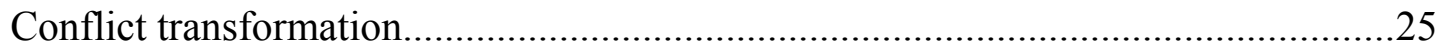

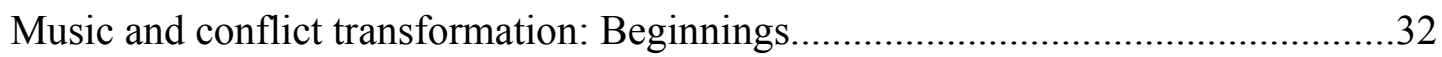

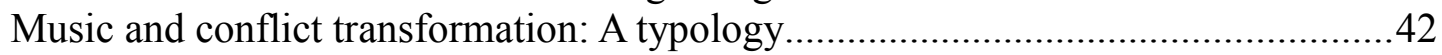

Music and conflict transformation: Recent developments.....................................44

Music and conflict transformation: A critique.........................................................54

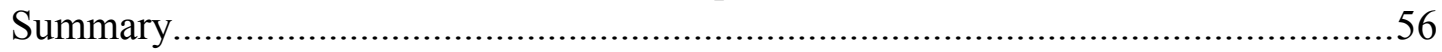

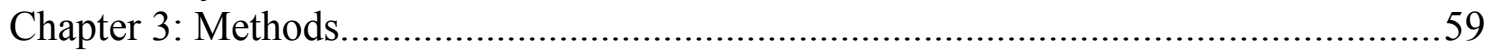

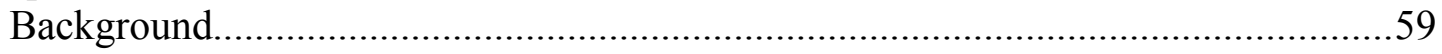

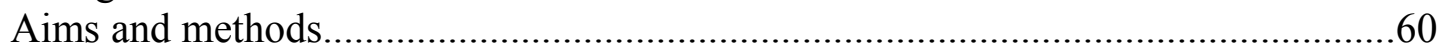

Summary of fieldwork sites and methods used......................................................63

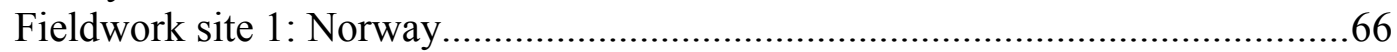

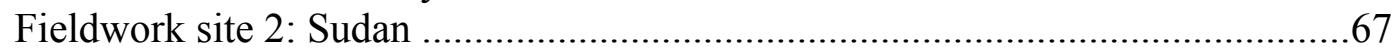

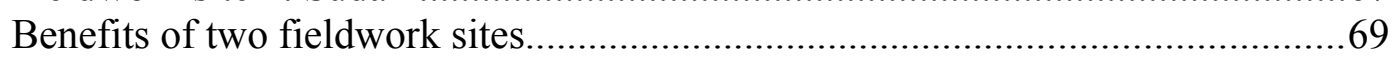

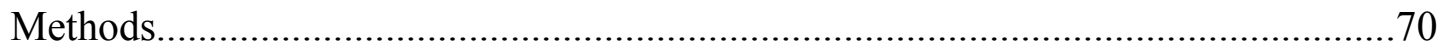

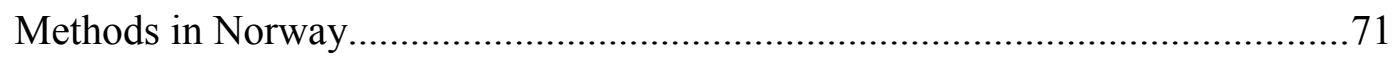

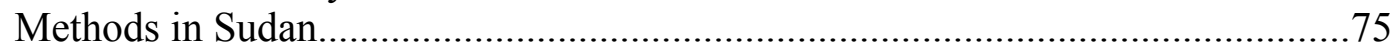

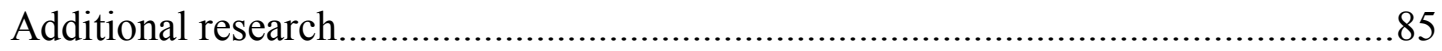

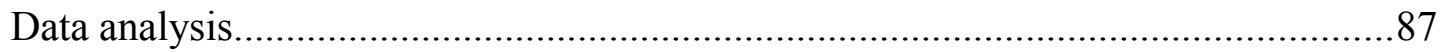

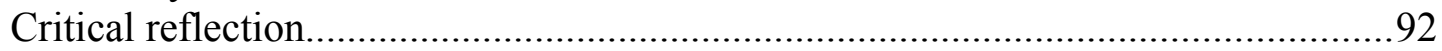

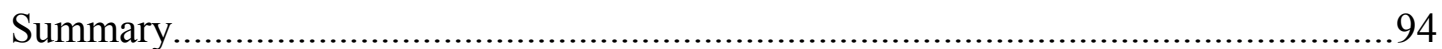

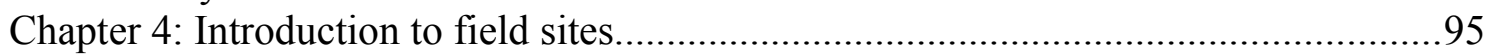

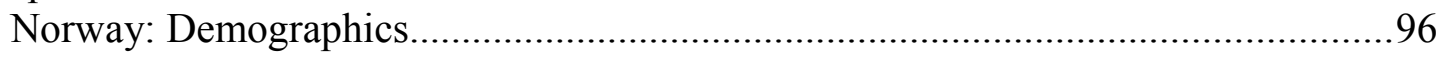

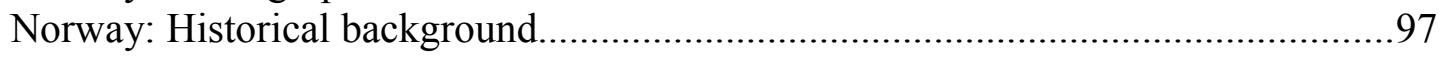

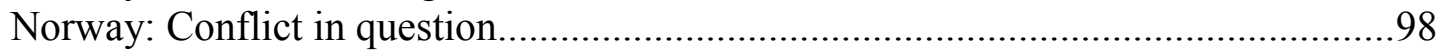

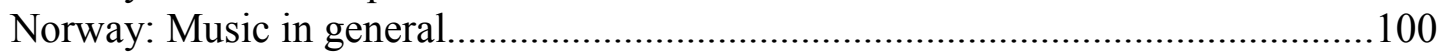

Norway: Background to conflict transformation research....................................101

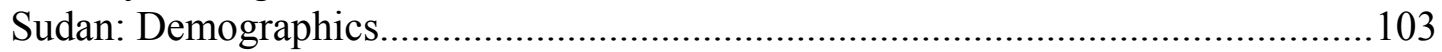

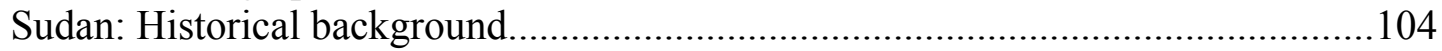

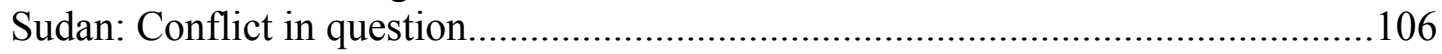

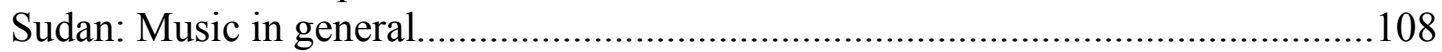

Sudan: Background to conflict transformation research.......................................110

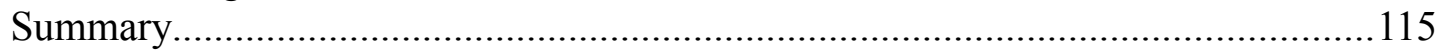

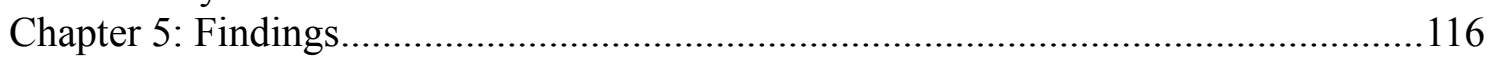

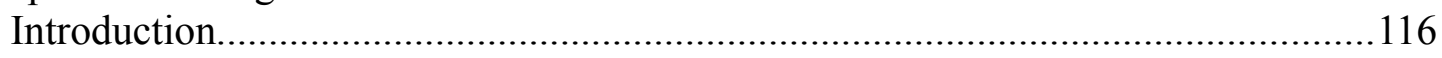

1. Participants' reflections on music and conflict transformation............................118 
I'd like to teach the world to sing: Music and conflict transformation by Arild Bergh

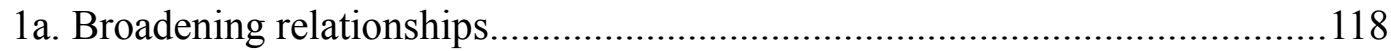

1b. Participants' own understanding of the musical events.................................131

1c. From joint active musicking to music as representation..............................136

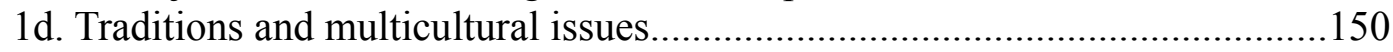

2. Socio-political context of music and conflict transformation..............................154

2a. Extra musical issues that affected the outcome.............................................154

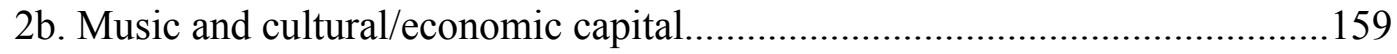

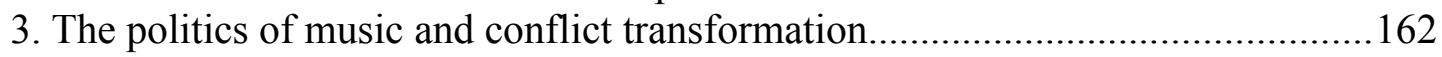

3a. Interventions, music coming into focus and out of locus.............................162

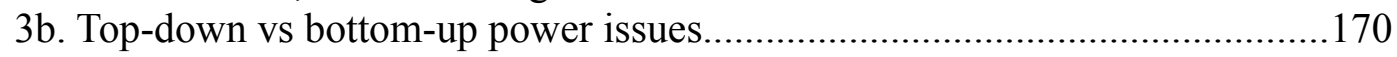

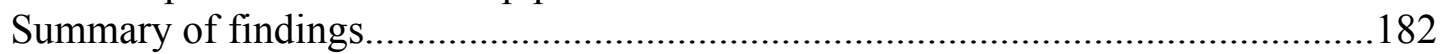

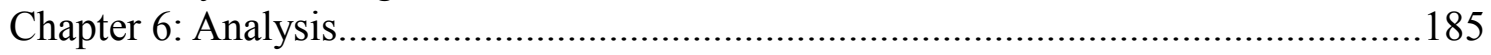

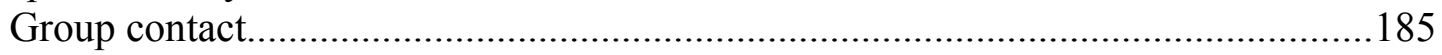

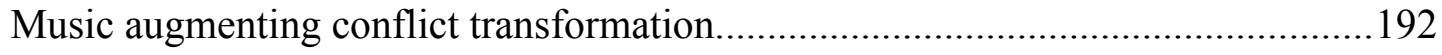

Music as interruption for conflict transformation purposes....................................197

Developing and transferring bonds: From music to everyday life.........................202

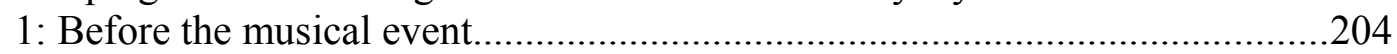

2: During the musical event............................................................................205

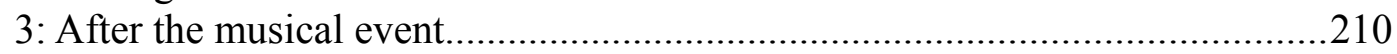

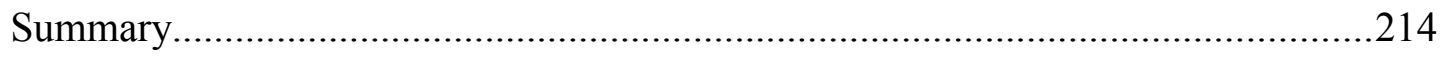

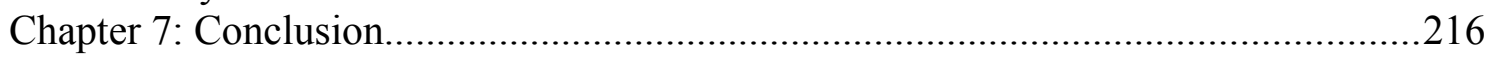

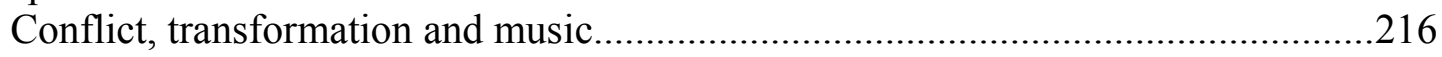

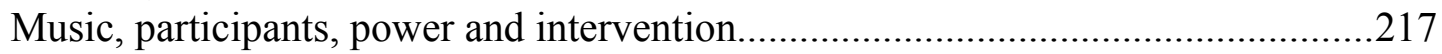

Music and conflict transformation in Norway and Sudan...................................220

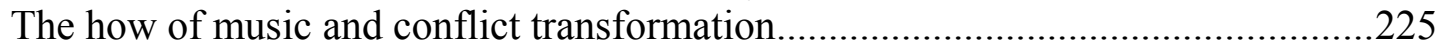

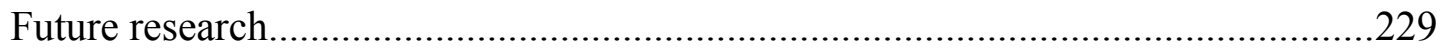

Final thoughts: Between conflict transformation and music...............................231

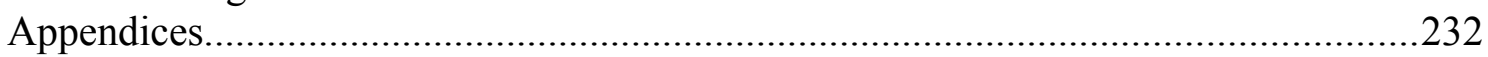

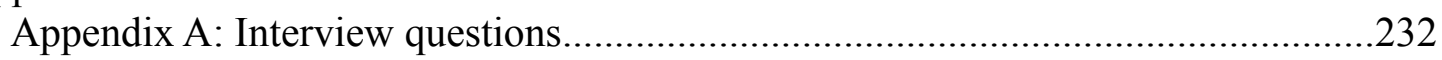

Interview schedule for fieldwork in Norway, former pupils............................232

Interview schedule for fieldwork in Norway, musicians....................................233

Interview schedule for fieldwork in Norway, teachers...................................233

Sudan: Semi-structured interview schedule for participants.............................235

Sudan: Semi-structured interview schedule for musicians...............................2.236

Sudan: Semi-structured interview schedule for organisers...............................236

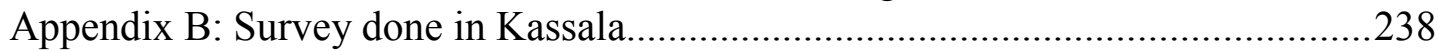

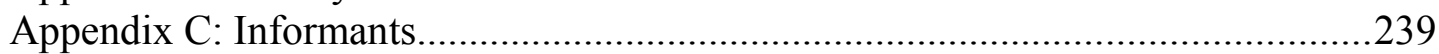

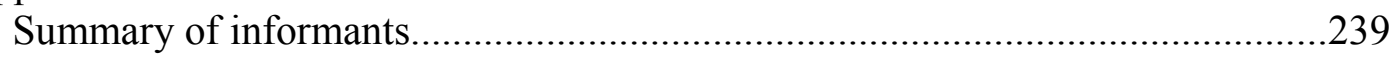

Informants names and background............................................................239

List of ethnic groups present Wau Nour............................................................243

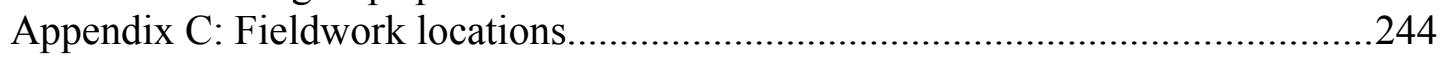

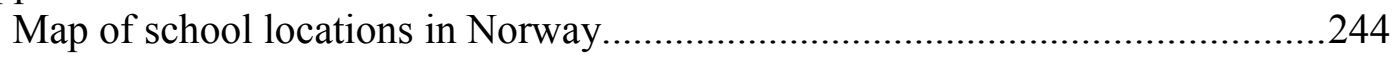

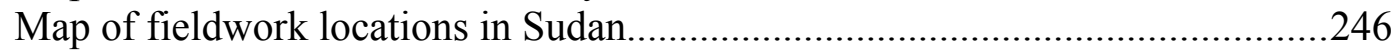

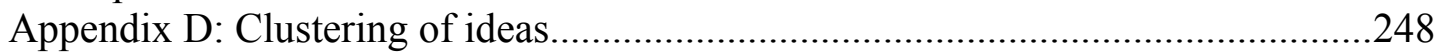

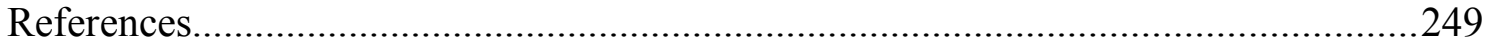




\section{Figures, tables and copyright}

\section{Figures}

Kassala survey results.

Video snapshots showing pupils at different schools engaging with African music.....129

Picture from Krongo concert showing audience non-participation.

Top-down network, strong ties $=$ bolder lines, stronger actors $=$ dark colour................174

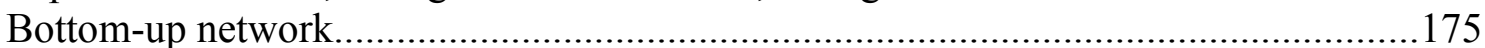

Overview map of school locations in Norway..........................................................24

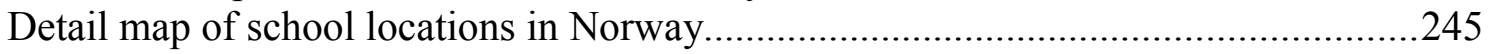

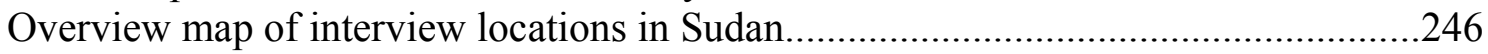

Detail map of interview locations in Sudan...............................................................24

Cluster from 2005, emerging themes (at that time) coded in different colours.............248

\section{Tables}

Norwegian timeline

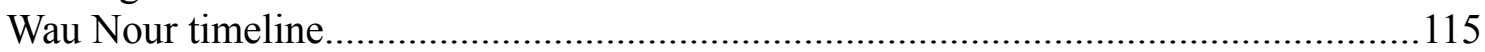

Group contact theory summary......................................................................... 190

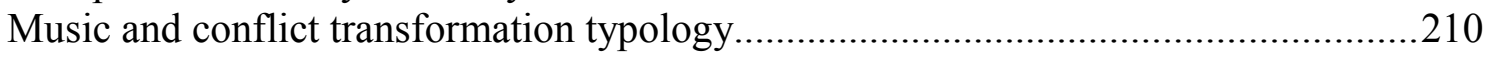

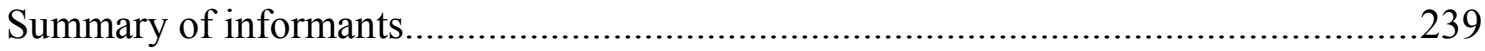

Full list of informants with background summary ...................................................242

\section{Note on copyright and translation}

Pictures used in this thesis are (C) Arild Bergh except where otherwise noted. All translations from Norwegian interviews or Norwegian source material by Arild Bergh. Interviews done in Arabic were originally translated by Muhammad Jalal Hashim with additional verification by Halim Sabbar. 


\section{Preface: How singing stopped war - but not alone}

The background to this thesis is encapsulated in the song and history of Christmas In The Trenches. ${ }^{1}$ This song by John McDermott recounts a particular aspect of the socalled Christmas Truce in 1914 when an impromptu ceasefire took place for several days between British, French and German troops, starting on Christmas Eve. The song recounts how British soldiers heard Stille Nacht (Silent Night) sung on the German side and how this prompted the ceasefire. The story of the truce and the singing of Stille Nacht is relatively well known and sometimes used to describe how powerful music can be.

Inspiring as this notion of a song stopping war is, it presents and perpetuates a particularly romantic view of music. In this view "the power of music" is a black box that works in mysterious and benign ways, regardless of context; in this thesis I will demonstrate how this affects music and conflict transformation. Due to the almost magic nature of music in this view, there is no need to explore further what happens; therefore we never learn how music may actually function in conflict or conflict transformation. This lack of explanation leaves us at the mercy of music and musicians should we ever want to use music in conflict transformation activities. However, if we refuse to accept this and insist on finding out more about what happened, what was the context and how music fitted into this context, a different picture emerges of music and the role of music. Filling in (parts of) this picture is the essence of this thesis.

Using the Christmas Truce as an example is instructive. We find that troops on both sides had been promised a quick victory but ended up in muddy trenches and were killed in their thousands every month. By Christmas there was considerable animosity and cynicism about one's own side among soldiers who had fought for some time at the front, and this tended to reduce hostility to the other side. A desire existed on both sides to bury their dead who had been lying in no man's land between the two sides for some time. Furthermore, in both Britain and Germany Christmas was strongly connected to family and peaceful celebrations; therefore considerable emotional priming had already taken place. However, the ceasefire did not start when Silent Night was sung. In the days before Christmas there had been spontaneous fraternising between the two sides.

$1 \mathrm{http}: / /$ www.youtube.com/watch? $\mathrm{v}=\mathrm{s} 9 \mathrm{coPzDx} 6 \mathrm{tA}$ 
I'd like to teach the world to sing: Music and conflict transformation by Arild Bergh

On Christmas Eve, the Germans (who had easier access to material goods from home) had been decorating trees, etc. thus clearly signifying their intent to celebrate Christmas. Later soldiers started singing back and forth and this went on for some time before they started shouting directly to each other. Germans held up placards saying that they would not shoot if the other side did not. Then the soldiers came up from the trenches (main source: Weintraub 2001).

The view promoted in the song Christmas In The Trenches, no matter how inspiring, do us a disservice by inflating the role of music, which is done largely by ignoring any context, thus making it seem as if music is always the key actor in the drama that unfolds. In this case a number of issues are ignored:

- Music was not used in isolation. It was yet another (very clear) signifier that one side considered celebrating Christmas, with all that this entailed (not shooting being the most important thing in this case) .

- Music did not on its own stop the soldiers from fighting. There were underlying issues that meant the soldiers were already tired of war. So much in fact that new troops had to be brought in many places to "break" the ceasefire.

- The Christmas songs were known by both sides, so it was very clear what they were. In other words, music "worked" because it resonated with both sides.

The history of, and myth around, the ceasefire and my response to it, represents this thesis in a nutshell. Although my purpose is not to belittle music, the reality of what happened shows that music tends to augment actions towards peace but rarely does so out of nothing. Music is action and interaction between human actors and therefore depends on human collusion for any changes to occur. Believing it to be otherwise does not necessarily make it so. In the end, the story about Stille Nacht and the ceasefire tells us more about those who recount it than about music itself. The purpose of this thesis therefore is to go beyond the lay theories and beliefs about music and what it can achieve in war and conflict situations in an attempt to see the real role of music in conflict transformation. Then, perhaps, we can start to use music for conflict transformation rather than hope that music can use us. 
I'd like to teach the world to sing: Music and conflict transformation by Arild Bergh

\section{Acknowledgements}

It has been said that it takes a village to raise a child. Likewise, creating a thesis also requires a community, in this case an international network of immensely knowledgeable, friendly and helpful people. I owe many people a debt of gratitude for their help and advice.

Three people deserve a special mention. My daughter Maia whose warm support made all the difference during the long process from initial thought to final thesis. My supervisor extraordinaire, Tia DeNora, must be thanked for coping with my argumentative ways and supporting me professionally and personally, with a great deal of humour. Last but not least, Mariko, my colleague and friend helped me as a discussion partner, sociologist and friend. Thank you all three, I could not have made it without your help.

Any social research is only as good as the data it obtains. My informants in Norway and Wau Nour, in particular al-Shafi and Hamad, therefore deserve a heartfelt thank you for taking the time to talk to me and furnish me with your insights and memories. I would also like to extend my gratitude to the employees of the project organisers in Norway and Sudan, without your information and help I would have missed out a lot of detail.

I received a great deal of help from the academic community around the world in my work in Norway and Sudan. In Norway Kjell Skyllstad provided considerable help with background material and contacts for my research there and it is appreciated deeply.

My fieldwork in Sudan was unusual for a sociologist, but without the Sudanese data this would be a lesser thesis. Muhamad Jalal Hashim was an indispensable colleague and ally in Sudan. Come practical or academic issues, he always had the answer. Herman Bell deserves special thanks for suggesting that I embark on this $\mathrm{PhD}$ in the first place, for coming with me to Sudan and introducing me to his extensive network and for the final proofreading. I am also indebted to the Sudan Academy of Sciences who invited me to Sudan and Babiker Kelaibai and his students at Alsharg Ahlia College in Kassala who at short notice helped conduct a survey in Kassala. Ali al- 
l'd like to teach the world to sing: Music and conflict transformation by Arild Bergh

Daw from the University of Khartoum kindly arranged a public talk for me to discuss my findings. Finally, Halim Sabbar helped me verify and clarify the data from Sudan at short notice; thank you.

I would like to thank John Sloboda for his generosity in supporting and promoting a beginner in the academic field and for many stimulating conversations and Jeneve Brooks for reading through this thesis and providing many helpful suggestions.

I also want to thank everyone from the SocArts group at Exeter for stimulating discussions, great company in Exeter and at conferences around the world as well as fun times with chocolate: Sophia, Mariko, Sue, Kari, Ian, Simon, Pedro, Craig, Trever, Pinar and Sigrun.

Finally, I want to thanks all of you who I have met in academic settings around the world or who have contacted me to discuss music and conflict transformation. By taking time from your busy schedules you helped improve my research through answers, comments, questions, networking and friendly chats. "None mentioned, none forgotten" as the saying goes, but you know who you are and I hope our paths will cross again.

Arild Bergh, $31^{\text {st }}$ January 2010 